Adherence to special diets and its association with meeting the nutrient recommendations in individuals with type 1 diabetes

\author{
Ahola, A. J.
}

2018-08

Ahola , A J , Forsblom , C \& Groop , P-H 2018 , ' Adherence to special diets and its association with meeting the nutrient recommendations in individuals with type 1 diabetes ' , Acta Diabetologica , vol. 55 , no. 8 , pp. 843-851 . https://doi.org/10.1007/s00592-018-1159-2

http://hdl.handle.net/10138/303664

https://doi.org/10.1007/s00592-018-1159-2

publishedVersion

Downloaded from Helda, University of Helsinki institutional repository.

This is an electronic reprint of the original article.

This reprint may differ from the original in pagination and typographic detail.

Please cite the original version. 


\title{
Adherence to special diets and its association with meeting the nutrient recommendations in individuals with type 1 diabetes
}

\author{
A. J. Ahola ${ }^{1,2,3}$ (C) C. Forsblom ${ }^{1,2,3} \cdot$ Per-Henrik Groop ${ }^{1,2,3,4}$
}

Received: 15 February 2018 / Accepted: 9 May 2018 / Published online: 18 May 2018

(c) Springer-Verlag Italia S.r.l., part of Springer Nature 2018

\begin{abstract}
Aims Not much is known about adherence to special diets in type 1 diabetes, characteristics of individuals with special diets, and whether such practices should raise concerns with respect to meeting the dietary recommendations. In this study, we assessed the frequencies of adherence to special diets, in a population of individuals with type 1 diabetes, and investigated the association between special diet adherence and dietary intake, measured as dietary patterns and nutrient intakes.

Methods During the Finnish Diabetic Nephropathy Study visit, participants with type 1 diabetes $(n=1429)$ were instructed to complete a diet questionnaire inquiring about the adherence to special diets. The participants also completed a food record, from which energy and nutrient intakes were calculated.

Results In all, 36.6\% participants reported adhering to some special diet. Most commonly reported special diets were lactose-free (17.1\%), protein restriction (10.0\%), vegetarian (7.0\%), and gluten-free (5.6\%) diet. Special diet adherents were more frequently women, older, had longer diabetes duration, and more frequently had various diabetes complications. Mean carbohydrate intakes were close to the lower levels of the recommendation in all diet groups, which was reflected in low mean fibre intakes but high frequencies of meeting the sucrose recommendations. The recommendation for saturated fatty acid intake was frequently unmet, with the highest frequencies observed in vegetarians. Of the micronutrients, vitamin $\mathrm{D}$, folate, and iron recommendations were most frequently unmet, with some differences between the diet groups.

Conclusions Special diets are frequently followed by individuals with type 1 diabetes. The adherents are more frequently women, and have longer diabetes duration and more diabetes complications. Achieving the dietary recommendations differed between diets, and depended on the nutrient in question. Overall, intakes of fibre, vitamin D, folate, and iron fell short of the recommendations.
\end{abstract}

Keywords Adherence $\cdot$ Dietary recommendations $\cdot$ Special diets $\cdot$ Type 1 diabetes

Managed by Massimo Federici.

Electronic supplementary material The online version of this article (https://doi.org/10.1007/s00592-018-1159-2) contains supplementary material, which is available to authorized users.

Per-Henrik Groop

per-henrik.groop@helsinki.fi

1 Folkhälsan Institute of Genetics, Folkhälsan Research Center, University of Helsinki, Biomedicum Helsinki C318b, PO Box 63, 00014 Helsinki, Finland

2 Abdominal Center Nephrology, University of Helsinki and Helsinki University Central Hospital, Helsinki, Finland

3 Research Programs Unit, Diabetes and Obesity, University of Helsinki, Helsinki, Finland

4 Department of Diabetes, Central Clinical School, Monash University, Melbourne, VIC, Australia

\section{Introduction}

Dietary guidelines, targeted at individuals with diabetes, aim at good glycaemic control, healthy body weight, and prevention of diabetic complications [1], while allowing sufficient flexibility to ensure good quality of life [2]. Despite the specific challenges related to the daily management of diabetes, the current dietary recommendations for patients with diabetes are no different from the ones recommended for the healthy population [3, 4]. While these general dietary recommendations form the basis for the diabetes nutrition therapy, this does not mean that there is one diet that fits all individuals with diabetes. Instead, it is increasingly recognized that diet may be individualized to take into account the patient's specific requirements and preferences [1]. Therefore, although management of diabetes does not call for 
any special diet, individuals with diabetes may still follow a variety of special diets for a number of reasons. With special diets, we refer to diet regimens used to address specific nutritional, physiological, medical, or psychological goals.

To the best of our knowledge, the prevalence of adherence to special diets in individuals with type 1 diabetes has not previously been investigated. In an Italian study of the adult general population, the rate of adhering to any special diet was $6.2 \%$ [5]. Of these, a low-energy diet used for weight reduction was the most prevalent, accounting for more than $55 \%$ of the special diets. In a large American population of non-hospitalized adults, only $2.9 \%$ of the respondents reported having adhered to one or more special diets over the past 12 months [6]. The surprisingly low rate of special diets in that study may be explained by the fact that only vegetarian, macrobiotic, Atkins, Pritikin, and Ornish diets were included. Importantly, these diets may not be the most relevant ones among individuals with type 1 diabetes. While various vegetarian diets are probably prevalent also in this patient population, diets such as lactose-free, gluten-free, and protein restriction may also be frequently adopted.

In addition to the obvious gap in the knowledge regarding the prevalence of adherence to special diets, in type 1 diabetes, we do not know whether such practices should raise concern with respect to insufficiencies in nutrient intakes. After all many diets, such as gluten-free, vegetarian, and protein restriction are based on the elimination or significant reduction in one or more of the food items. Moreover, as diet plays a major role in the daily management of metabolic disorders like type 1 diabetes, it would be important to know whether adherence to a particular special diet is associated with a more favourable clinical profile or even better longterm outcomes.

Our aim was to assess the frequencies of adherence to special diets in a large population of individuals with type 1 diabetes, participating in the Finnish Diabetic Nephropathy (FinnDiane) Study, to investigate the association between special diet adherence and dietary intake, measured as dietary patterns and nutrient intakes.

\section{Methods}

The study subjects were individuals with type 1 diabetes participating in the nationwide, multicentre FinnDiane Study. From all participants which we included, in the current analyses, those who had completed the diet questionnaire within 2 years of the study visit $(n=1429,45.5 \%$ men, mean \pm standard deviation age $47 \pm 14$ years). Type 1 diabetes was assumed if diabetes was diagnosed before the age of 35 years, and permanent insulin treatment was initiated within 1 year of the diagnosis. The study protocol was approved by the Ethics Committee of the Helsinki and Uusimaa Hospital District as well as by the local ethics committees at each centre. Written informed consent was obtained from each participant prior to participation.

At the FinnDiane Study visits, the participants were asked to complete a validated [7] diet questionnaire, as previously described [8]. In short, with this questionnaire, we aimed at obtaining information on the subjects' dietary habits. As part of the questionnaire, we enquired whether the participants followed any special diet (yes/no). If yes, the participants were asked to report all that apply from multiple choices (lactose-free, gluten-free, protein restricted, and vegetarian diet). The participants also reported whether or not the choice to adhere to a particular diet was based on a diagnosis or a recommendation from a health care provider. Other types of special diets were reported in the provided space. In the same form was embedded a food frequency questionnaire (FFQ). In this FFQ, the participants reported on a sevenpoint scale the consumption frequencies of some of the most common food items in Finland [9]. The reported frequencies were subsequently transformed into pseudo continuous variables that describe the monthly consumption frequencies (e.g., once a day was recoded as 28 , and once a week as 4 ). These variables were analysed with an exploratory factor analysis to reveal patterns in the dietary intake, as described in the statistical analyses.

With 2-3 month interval, the participants completed a 3-day ( 2 weekdays and 1 weekend day) exercise and food record twice [8]. Dietary intake was recorded using common household measures, and the continuation of the habitual practices over the record-keeping days was emphasised. The food record entries were subsequently recorded in the AivoDiet software (version 2.0.2.3, AIVO, Turku, Finland), based on the Finnish National Food Composition Database, which was used to calculate the mean energy and nutrient intakes over the record-keeping days. The calculated intakes were compared with the dietary recommendations by the National Nutrition Council [4]. For the current analyses, involving energy and nutrient intakes, we included all participants with food records over a minimum of 3 days and with plausible energy intake (5021-14,644 kJ) $(n=1040)$.

The procedures conducted at the FinnDiane Study visit have previously been described [10]. In short, the participants' height and weight were measured in light clothing. These measurements were used to calculate body mass index $\left(\mathrm{BMI} ; \mathrm{kg} / \mathrm{m}^{2}\right.$ ). Seated blood pressure was measured twice after a minimum of 10-min rest, and the mean of the measurements was calculated. Early morning blood samples were drawn and shipped for central determination of serum lipid, lipoprotein, and creatinine concentrations. Fasting was not required, and a light (low-fat) breakfast was accepted to prevent or treat hypoglycaemia. Using the CKD-EPI formula [11], serum creatinine concentration was used to calculate estimated glomerular filtration rate (eGFR). $\mathrm{HbA}_{1 \mathrm{c}}$ was 
measured locally using standardized assays. The attending physician recorded the patient's diabetes complications on a standardized form. Proliferative retinopathy was defined as retinal laser treatment. A cardiovascular event was defined as any major cardiovascular event (acute myocardial infarction, coronary bypass, stroke, amputation, or peripheral vascular disease).

For basic characteristics, categorical variables are presented as frequencies (\%), normally distributed continuous variables as mean \pm standard deviation (SD), and non-normally distributed continuous variables as median (interquartile range). The respective between-group comparisons were done using Chi-squared test, independent-samples $t$ test, and Mann-Whitney $U$ test. We used exploratory factor analysis (maximal-likelihood and varimax rotation) to identify underlying dietary constructs from the FFQ data. In this analysis, we included all factors with eigenvalues $>1.0$ while, within each factor, food items with a factor loading $|\geq 0.20|$ were included. The formed factors (or dietary patterns) were intuitively named based on the food items included. The factor score was the sum of the scores for all items associated with that particular factor multiplied by its corresponding factor loading. The adjusted factor scores are presented as mean \pm standard error, and the between-group comparison in these scores was done with a generalized linear model. Although all values were not normally distributed, the food record-derived energy and nutrient intakes are presented as mean \pm SD to enable comparison between the groups. The nutrient intakes were compared against the dietary recommendations [4], and the percentage of individuals meeting each of the recommendation was calculated. All analyses were conducted using IBM SPSS Statistics for Windows, Version 22.0 (IBM Corp, Armonk, NY, USA). A two-tailed $P$ value $<0.05$ was considered statistically significant.

\section{Results}

In all, 1429 participants completed the diet questionnaire with information on the adherence to special diets. Of these, $36.6 \%$ reported following some special diet (Table 1). The most commonly reported special diet was lactose-free diet $(17.1 \%)$, followed by protein restricted $(10.0 \%)$, vegetarian $(7.0 \%)$, and gluten-free $(5.6 \%)$ diet. Of these, protein restriction $(78.3 \%)$ and gluten-free diet $(73.8 \%)$ were most commonly initiated based on a diagnosis or recommendation by a health care provider (Fig. 1). In all, $41.1 \%$ of those adhering to a lactose-free diet, and $10.0 \%$ of those adhering to vegetarian diet, reported having initiated the diet based on a diagnosis or recommendation from a health care personnel.

Altogether, $146(10.2 \%)$ individuals reported adhering to more than one special diet. Of these 111 adhered to two special diets, while 30 and 5 adhered to three and four special diets, respectively. Lactose-free diet was the most common combination in those reporting protein restriction (28.7\%), vegetarian $(22.0 \%)$, and gluten-free $(36.3 \%)$ diets. Among those adhering to lactose-free diet, protein restriction $(14.3 \%)$ was the most common combination, followed by gluten-free $(11.9 \%)$ and vegetarian $(9.0 \%)$ diets.

A total of 141 (9.9\%) participants reported adhering to some other special diet. Of these, avoidance of various food allergens (2.8\%) was most frequently reported. This was followed by carbohydrate restricted (1.5\%), sugar-free (1.0\%), red meat restricted $(0.9 \%)$, milk-free $(0.7 \%)$, fat restricted $(0.5 \%)$, high protein $(0.4 \%)$, fermentable oligo-, di-, monosaccharide and polyol restricted $(0.3 \%)$, weight reduction $(0.3 \%)$, gastroparesis $(0.2 \%)$, gallbladder $(0.1 \%)$, and yeastfree $(0.1 \%)$ diets. Due to the great variety of reported diets and a relatively small number of subjects in each individual diet category, these groups were not analysed further.

Compared to those not following any special diet, those adhering to any special diet, as well as those reporting multiple special diets, were more frequently women, were older, had longer diabetes duration, and had more frequently various diabetes complications. Diabetes duration was longer in all the special diet groups, compared to the group with no special diet. Also median eGFR values were lower, and proliferative retinopathy was more prevalent. Moreover, compared to those with no special diet, cardiovascular events were more common in all the special diet groups, except in the vegetarians and in those adhering to a gluten-free diet.

Seven diet patterns were formed in the factor analysis of the FFQ data (Table 2). Compared to individuals not following any special diet, those adhering to lactose-free diet had higher factor scores in the "Vegetables and fish", and "Modern" patterns, but lower scores in the "Soft drinks" pattern (Table 3). Individuals on protein restriction, scored higher in "Vegetables and fish", but lower in "Meat and potatoes" and "Soft drinks" patterns. Vegetarians had, as expected, higher scores in the "Vegetables and fish" pattern, but lower in the "Modern", and the "Meat and potatoes" patterns. Those on gluten-free diet got higher scores in the "Modern" and "Healthy snack" patterns. Finally, compared to those not on any special diet, those reporting multiple special diets scored higher in the "Vegetables and fish", and "Modern" patterns, but lower in the "Meat and potatoes", and "Soft drinks" patterns.

The food record, used to calculate energy and nutrient intakes, was available from 1040 (72.8\%) participants. Compared to the group with no special diets, those reporting lactose-free, and vegetarian diets more frequently achieved the carbohydrate recommendations (Table 4). The mean fibre intake, measured as grams per day, was below recommendations in all groups, and ranged from $18.5 \mathrm{~g} / \mathrm{day}$ in those on gluten-free diet to $23.3 \mathrm{~g} /$ day in vegetarians. Vegetarians achieved more frequently the energy-adjusted 
Table 1 Basic characteristics of the study subjects divided by self-reported adherence to special diets

\begin{tabular}{|c|c|c|c|c|c|c|c|}
\hline & $\begin{array}{l}\text { None } \\
n=906(63.4 \%)\end{array}$ & $\begin{array}{l}\text { Any special diet } \\
n=523(36.6 \%)\end{array}$ & $\begin{array}{l}\text { Lactose-free } \\
n=244(17.1 \%)\end{array}$ & $\begin{array}{l}\text { Protein restric- } \\
\text { tion } \\
n=143(10.0 \%)\end{array}$ & $\begin{array}{l}\text { Vegetarian } \\
n=100(7.0 \%)\end{array}$ & $\begin{array}{l}\text { Gluten-free } \\
n=80(5.6 \%)\end{array}$ & $\begin{array}{l}\text { Multiple diets } \\
n=146(10.2 \%)\end{array}$ \\
\hline $\begin{array}{l}\text { Recommended }{ }^{\mathrm{a}}, \\
n(\%)\end{array}$ & NA & NA & $100(41.1)$ & $112(78.3)$ & $10(10.0)$ & $59(73.8)$ & NA \\
\hline $\begin{array}{l}\text { Lactose-free, } \\
n(\%)\end{array}$ & NA & $244(17.1)$ & NA & $41(28.7)$ & $22(22.0)$ & $29(36.3)$ & NA \\
\hline $\begin{array}{l}\text { Protein restric- } \\
\text { tion, } \mathrm{n}(\%)\end{array}$ & NA & 143 (13.6) & $35(14.3)$ & NA & $19(19.0)$ & $12(15.0)$ & NA \\
\hline $\begin{array}{l}\text { Vegetarian, } n \\
\quad(\%)\end{array}$ & NA & $100(7.0)$ & $22(9.0)$ & $19(13.3)$ & NA & $8(10.0)$ & NA \\
\hline $\begin{array}{l}\text { Gluten-free, } \\
n(\%)\end{array}$ & NA & $80(5.6)$ & $29(11.9)$ & $12(8.4)$ & $8(8.0)$ & NA & NA \\
\hline $\begin{array}{l}\text { Other special } \\
\text { diet, } n(\%)\end{array}$ & NA & $141(10.2)$ & $41(16.8)$ & $59(41.3)$ & $11(11.0)$ & $19(23.8)$ & NA \\
\hline Men, $\%$ & 50.6 & $36.7 * * *$ & $34.8 * * *$ & 49.0 & $34.0 * *$ & $35.0^{* *}$ & $33.6^{* * *}$ \\
\hline Age, years & $46(36-57)$ & $49(38-59)^{*}$ & $49(38-60)^{*}$ & $52(47-59) * * *$ & $47(35-58)$ & $49(40-57)$ & $53(43-61)^{* * *}$ \\
\hline $\begin{array}{l}\text { Diabetes dura- } \\
\text { tion, years }\end{array}$ & $28(19-39)$ & $33(22-43)^{* * *}$ & $32(21-43)^{* *}$ & $39(30-46)^{* * *}$ & $32(22-42)^{*}$ & $33(22-43)^{*}$ & $35(26-44) * * *$ \\
\hline $\begin{array}{l}\text { Proliferative } \\
\quad \text { retinopathy, \% }\end{array}$ & 30.0 & $49.8 * * *$ & $45.5^{* * *}$ & $81.7 * * *$ & $47.0 * *$ & $44.3 *$ & $61.6^{* * *}$ \\
\hline$\underset{\%}{\operatorname{Hard} \mathrm{CV} \text { event }}{ }^{\mathrm{b}}$ & 12.0 & $23.5^{* * *}$ & $21.5^{* * *}$ & $41.5^{* * *}$ & 18.0 & 16.3 & $28.5^{* * *}$ \\
\hline $\begin{array}{l}\text { eGFR, } \mathrm{ml} / \\
\mathrm{min} / 1.73 \mathrm{~m}^{2}\end{array}$ & $101(86-112)$ & $90(59-108)^{* * *}$ & $94(66-108)^{* * *}$ & $41(11-74) * * *$ & $94(70-112)^{*}$ & $92(70-103)^{* * *}$ & $71(34-95)^{* * *}$ \\
\hline low eGFR, \% & 2.4 & $14.9 * * *$ & $10.2 * * *$ & $42.1 * * *$ & $10.0 * * *$ & $9.2 * *$ & $23.8 * * *$ \\
\hline BMI, $\mathrm{kg} / \mathrm{m}^{2}$ & $25.6(23.2-28.1)$ & $\begin{array}{l}25.5(23.1- \\
29.0)\end{array}$ & $\begin{array}{l}25.6(23.0- \\
29.1)\end{array}$ & $25.6(23.0-29.0)$ & $\begin{array}{l}25.5(23.0- \\
28.2)\end{array}$ & $\begin{array}{l}25.9(23.9- \\
28.7)\end{array}$ & $26.2(23.5-29.0)$ \\
\hline $\mathrm{SBP}, \mathrm{mmHg}$ & $137(125-151)$ & $138(125-151)$ & $136(125-149)$ & $\begin{array}{r}144(130- \\
164)^{* * *}\end{array}$ & $135(123-147)$ & $136(124-150)$ & $142(125-157)^{*}$ \\
\hline $\mathrm{DBP}, \mathrm{mmHg}$ & $78 \pm 10$ & $76 \pm 10^{*}$ & $77 \pm 9$ & $78 \pm 11$ & $74 \pm 10 * *$ & $75 \pm 10^{*}$ & $76 \pm 9$ \\
\hline $\begin{array}{l}\text { Total choles- } \\
\text { terol, } \mathrm{mmol} / \mathrm{l}\end{array}$ & $4.6(4.1-5.2)$ & $4.5(3.9-5.1)^{*}$ & $4.5(3.9-5.1)$ & $4.2(3.7-4.9)^{* * *}$ & $4.5(3.9-5.1)$ & $4.4(3.8-4.9)^{*}$ & $4.5(3.8-5.1)$ \\
\hline $\begin{array}{l}\text { HDL-choles- } \\
\text { terol, } \mathrm{mmol} / \mathrm{l}\end{array}$ & $1.57(1.29-1.88)$ & $\begin{array}{l}1.51(1.25- \\
1.84)^{*}\end{array}$ & $\begin{array}{l}1.55(1.27- \\
1.89)\end{array}$ & $\begin{array}{c}1.42(1.13- \\
1.71)^{* * *}\end{array}$ & $\begin{array}{l}1.51(1.23- \\
1.85)\end{array}$ & $\begin{array}{l}1.51(1.19- \\
1.82)\end{array}$ & $1.49(1.19-1.90)$ \\
\hline $\begin{array}{l}\text { Triglycerides, } \\
\mathrm{mmol} / \mathrm{l}\end{array}$ & $0.95(0.73-1.30)$ & $\begin{array}{c}1.05(0.76- \\
1.50)^{* *}\end{array}$ & $\begin{array}{l}1.03(0.75- \\
1.47)\end{array}$ & $\begin{array}{c}1.25(0.93- \\
1.71)^{* * *}\end{array}$ & $\begin{array}{l}1.03(0.74- \\
1.36)\end{array}$ & $\begin{array}{l}0.97(0.66- \\
1.36)\end{array}$ & $\begin{array}{l}1.11(0.79- \\
1.47)^{*}\end{array}$ \\
\hline $\begin{array}{l}\mathrm{HbA}_{\mathrm{lc}}, \mathrm{mmol} / \\
\mathrm{mol}\end{array}$ & $64(56-73)$ & $65(57-75)$ & $65(57-72)$ & $66(56-77)$ & $62(53-71)$ & $67(58-73)$ & $64(54-72)$ \\
\hline $\mathrm{HbA}_{1 \mathrm{c}}, \%$ & $8.0(7.3-8.8)$ & $8.1(7.4-9.0)$ & $8.1(7.4-8.7)$ & $8.2(7.3-9.2)$ & $7.8(7.0-8.6)$ & $8.3(7.5-8.9)$ & $8.0(7.1-8.7)$ \\
\hline
\end{tabular}

Data are presented as frequencies, median (interquartile range), or mean \pm standard deviation. Respective analyses, comparing each special diet group with the group without any special diet, were done with Chi-squared test, Mann-Whitney $U$ test, and independent sample's $t$ test $e G F R$ estimated glomerular filtration rate, low eGFR eGFR $<30 \mathrm{ml} / \mathrm{min} / 1.73 \mathrm{~m}^{2}, B M I$ body mass index, $S B P$ systolic blood pressure, $D B P$ diastolic blood pressure

$* P<0.05 ; * * P<0.01 ; * * * P<0.001$

${ }^{a}$ Whether special diet was initiated based on a diagnosis or recommendation from a health care personnel

${ }^{\mathrm{b}}$ Hard cardiovascular event, any major cardiovascular event (acute myocardial infarction, coronary bypass, stroke, amputation, and peripheral vascular disease)

recommendations of fibre intake as compared to those not following any special diet. Adherence to gluten-free diet was associated with the highest mean total fat intake and the lowest frequency of meeting the recommended levels of fat intake. Mean saturated fat intake was above the recommended levels in all groups. However, the highest proportion of individuals meeting these recommendations was observed in the vegetarians, and in those restricting their protein intake. The mean sucrose, monounsaturated fatty acid, polyunsaturated fatty acid, and protein intakes 


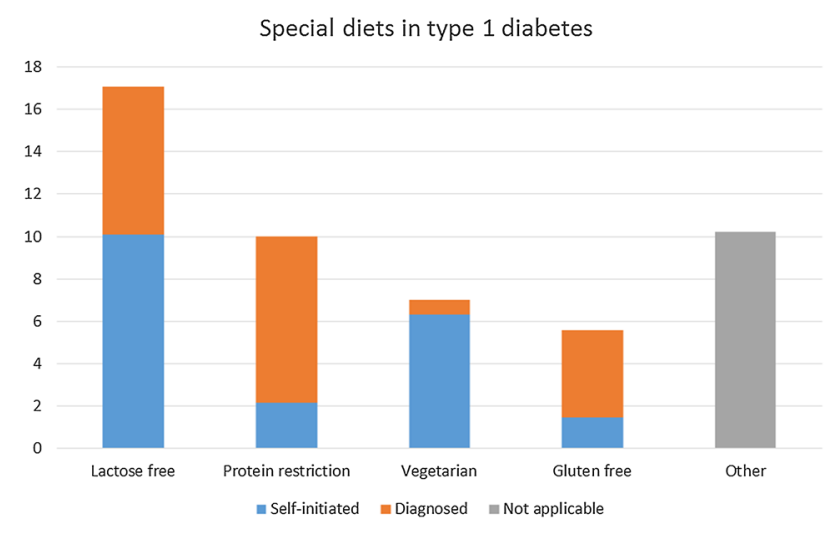

Fig. 1 Frequencies (\%) of adhering to special diets in a population 1429 individuals with type 1 diabetes, and whether the diet was initiated based on self-evaluation or based on a diagnosis or suggestion from a health care provider

were within the recommended levels in all groups, and this was reflected in the high percentages of individuals meeting these recommendations. Compared to those with no special diets, protein intake, measured as protein $(\mathrm{g})$ per weight $(\mathrm{kg})$, was lower in all other special diet groups except in those with gluten-free diet.

Of the energy-adjusted vitamin and mineral intakes, the mean intakes of all other nutrients but vitamin $\mathrm{D}$, and folate reached the recommended levels in all groups (Table 5). Compared to those not following any special diet, the proportion of individuals meeting the vitamin D recommendations was particularly low in the group adhering to lactosefree diet. Moreover, only $18 \%$ of those on gluten-free diet met the recommendations for vitamin D intake. The frequencies of meeting the folate recommendations were low in all groups, with the highest frequencies observed in the vegetarians and in those following a gluten-free diet. Protein restriction, compared to the group with no special diet, was associated with significantly lower frequency of meeting the calcium recommendations. Finally, in those reporting lactose-free, gluten-free, and no special diet, less than 50\% achieved the recommendations for iron intake.
Table 2 Factor analysis-derived dietary patterns

\begin{tabular}{|c|c|c|c|c|}
\hline Diet pattern & Eigenvalue & $\%$ of variance & Included food items & Factor loadings \\
\hline \multirow[t]{5}{*}{ Vegetables and fish } & 2.262 & 11.906 & Cooked vegetables & 0.819 \\
\hline & & & Legumes & 0.486 \\
\hline & & & Fresh vegetables & 0.429 \\
\hline & & & Fruits and berries & 0.259 \\
\hline & & & Fish & 0.203 \\
\hline \multirow[t]{5}{*}{ Modern } & 1.911 & 10.058 & Poultry & 0.841 \\
\hline & & & Pasta and rice & 0.400 \\
\hline & & & Fried and grilled foods & 0.345 \\
\hline & & & Meat dishes & 0.313 \\
\hline & & & Eggs & 0.215 \\
\hline \multirow[t]{3}{*}{ Sweet } & 1.605 & 8.449 & Sweet pastry & 0.684 \\
\hline & & & Sweets and chocolate & 0.560 \\
\hline & & & Ice cream & 0.338 \\
\hline \multirow[t]{3}{*}{ Meat and potatoes } & 1.387 & 7.299 & Meat dishes & 0.682 \\
\hline & & & Potato & 0.464 \\
\hline & & & Sausages and cold cuts & 0.351 \\
\hline \multirow[t]{4}{*}{ Healthy snack } & 1.341 & 7.060 & Fruits and berries & 0.691 \\
\hline & & & Yoghurt and curd & 0.386 \\
\hline & & & Fresh vegetables & 0.326 \\
\hline & & & Low-fat cheese & 0.221 \\
\hline \multirow[t]{3}{*}{ Cheese and eggs } & 1.081 & 5.692 & Full-fat cheese & 0.595 \\
\hline & & & Low-fat cheese & -0.504 \\
\hline & & & Eggs & 0.237 \\
\hline \multirow[t]{3}{*}{ Soft drinks } & 1.013 & 5.330 & Soft drink & 0.296 \\
\hline & & & Fruits and berries & -0.269 \\
\hline & & & Cooked vegetables & -0.209 \\
\hline
\end{tabular}

Eigenvalues are the variances of the factors; \% of variance represents the percent of total variance accounted by each factor; factor loadings show the correlation of each food item with the given dietary pattern 
Table 3 Diet questionnaire-derived factor scores divided by self-reported adherence to a special diet $(n=1429)$

\begin{tabular}{lcccccc}
\hline & \multicolumn{1}{l}{ None } & Lactose-free & Protein restriction & Vegetarian & Gluten-free & Multiple diets \\
\hline Vegetables and fish & $-0.10 \pm 0.03$ & $0.03 \pm 0.06^{*}$ & $0.21 \pm 0.09^{* *}$ & $0.67 \pm 0.10^{* * *}$ & $-0.03 \pm 0.10$ & $0.32 \pm 0.09^{* * *}$ \\
Modern & $-0.01 \pm 0.03$ & $0.14 \pm 0.06^{*}$ & $-0.15 \pm 0.09$ & $-0.64 \pm 0.09 * * *$ & $0.51 \pm 0.11^{* * *}$ & $0.26 \pm 0.09^{* *}$ \\
Sweet & $0.02 \pm 0.03$ & $-0.01 \pm 0.06$ & $0.06 \pm 0.09$ & $0.02 \pm 0.09$ & $0.13 \pm 0.10$ & $-0.02 \pm 0.09$ \\
Meat and potatoes & $0.07 \pm 0.03$ & $-0.04 \pm 0.06$ & $-0.14 \pm 0.09^{*}$ & $-0.66 \pm 0.09 * * *$ & $0.02 \pm 0.10$ & $-0.30 \pm 0.08^{* * *}$ \\
Healthy snack & $-0.04 \pm 0.03$ & $0.00 \pm 0.06$ & $-0.02 \pm 0.09$ & $0.06 \pm 0.09$ & $0.20 \pm 0.10^{*}$ & $-0.01 \pm 0.08$ \\
Cheese and eggs & $0.02 \pm 0.03$ & $-0.06 \pm 0.06$ & $-0.06 \pm 0.08$ & $-0.05 \pm 0.09$ & $0.00 \pm 0.09$ & $-0.09 \pm 0.08$ \\
Soft drinks & $0.05 \pm 0.02$ & $-0.05 \pm 0.04^{*}$ & $-0.13 \pm 0.06^{*}$ & $0.17 \pm 0.07$ & $0.03 \pm 0.07$ & $-0.15 \pm 0.06^{* *}$ \\
\hline
\end{tabular}

Data are presented as mean \pm standard error. Positive and negative values refer to higher and lower intakes of the high-loading food items in each dietary pattern, respectively. Comparisons between those adhering and not adhering to special diets have been made with generalized linear model. All models are adjusted for age, sex, and eGFR status

$* P<0.05 ; * * P<0.01 ; * * * P<0.001$

Table 4 Mean energy, macronutrient, and fibre intakes of the study subjects completing the food record $(n=1040)$, and percentages of individuals reaching the recommendations divided by self-reported adherence to a special diet

\begin{tabular}{|c|c|c|c|c|c|c|}
\hline Nutrient (recommendation) & $\begin{array}{l}\text { None } \\
n=673(64.7 \%)\end{array}$ & $\begin{array}{l}\text { Lactose-free } \\
n=174(16.7 \%)\end{array}$ & $\begin{array}{l}\text { Protein restriction } \\
n=84(8.1 \%)\end{array}$ & $\begin{array}{l}\text { Vegetarian } \\
n=69(6.6 \%)\end{array}$ & $\begin{array}{l}\text { Gluten-free } \\
n=61(5.9 \%)\end{array}$ & $\begin{array}{l}\text { Multiple diets } \\
n=97(9.3 \%)\end{array}$ \\
\hline Energy, kJ & $8234 \pm 1921$ & $7699 \pm 1745^{* *}$ & $7051 \pm 1398 * * *$ & $7400 \pm 1566^{* *}$ & $8092 \pm 2140$ & $7551 \pm 1882 * * *$ \\
\hline Carbohydrate (45-60 E\%) & $\begin{array}{l}42.1 \pm 6.8 \\
33.3\end{array}$ & $\begin{array}{l}43.3 \pm 6.9^{*} \\
42.0^{*}\end{array}$ & $\begin{array}{l}44.5 \pm 7.3^{* *} \\
42.9\end{array}$ & $\begin{array}{l}45.1 \pm 8.0^{* *} \\
46.4^{*}\end{array}$ & $\begin{array}{l}41.1 \pm 6.9 \\
34.4\end{array}$ & $\begin{array}{l}42.9 \pm 7.9 \\
40.2\end{array}$ \\
\hline Sucrose $(<10 \mathrm{E} \%)$ & $\begin{array}{l}7.2 \pm 3.5 \\
80.1\end{array}$ & $\begin{array}{l}8.0 \pm 3.6^{* *} \\
75.3\end{array}$ & $\begin{array}{l}8.0 \pm 3.9 \\
76.2\end{array}$ & $\begin{array}{l}8.3 \pm 3.7^{*} \\
71.0\end{array}$ & $\begin{array}{l}8.0 \pm 3.8 \\
78.7\end{array}$ & $\begin{array}{l}8.0 \pm 3.7 * \\
76.3\end{array}$ \\
\hline Fibre $(\geq 25 \mathrm{~g})$ & $\begin{array}{l}21.1 \pm 7.6 \\
21.5\end{array}$ & $\begin{array}{l}20.9 \pm 7.3 \\
25.9\end{array}$ & $\begin{array}{l}19.1 \pm 6.4^{*} \\
17.9\end{array}$ & $\begin{array}{l}23.3 \pm 7.8^{*} \\
30.4\end{array}$ & $\begin{array}{l}18.5 \pm 6.8^{*} \\
16.4\end{array}$ & $\begin{array}{l}20.2 \pm 6.4 \\
20.6\end{array}$ \\
\hline Fibre $(\geq 3 \mathrm{~g} / \mathrm{MJ})$ & $\begin{array}{l}2.6 \pm 0.8 \\
27.8\end{array}$ & $\begin{array}{l}2.7 \pm 0.9 \\
27.0\end{array}$ & $\begin{array}{l}2.7 \pm 0.9 \\
35.7\end{array}$ & $\begin{array}{l}3.2 \pm 0.9 * * * \\
49.3 * * *\end{array}$ & $\begin{array}{l}2.3 \pm 0.8^{*} \\
18.0\end{array}$ & $\begin{array}{l}2.7 \pm 0.8 \\
32.0\end{array}$ \\
\hline Total fat (25-40 E\%) & $\begin{array}{l}36.3 \pm 6.0 \\
73.1\end{array}$ & $\begin{array}{l}36.4 \pm 6.3 \\
73.0\end{array}$ & $\begin{array}{l}36.4 \pm 6.4 \\
64.3\end{array}$ & $\begin{array}{l}35.3 \pm 7.3 \\
66.7\end{array}$ & $\begin{array}{l}37.9 \pm 6.9^{*} \\
57.4^{*}\end{array}$ & $\begin{array}{l}37.1 \pm 6.7 \\
66.0\end{array}$ \\
\hline SAFA $(<10 \%)$ & $\begin{array}{l}12.9 \pm 2.9 \\
15.6\end{array}$ & $\begin{array}{l}12.7 \pm 2.9 \\
17.2\end{array}$ & $\begin{array}{l}12.3 \pm 3.0 \\
27.4 *\end{array}$ & $\begin{array}{l}12.1 \pm 3.8 \\
30.4 * *\end{array}$ & $\begin{array}{l}12.9 \pm 3.3 \\
16.4\end{array}$ & $\begin{array}{l}12.3 \pm 3.1 \\
25.8 *\end{array}$ \\
\hline MUFA (10-20 E\%) & $\begin{array}{l}12.3 \pm 2.5 \\
83.1\end{array}$ & $\begin{array}{l}12.4 \pm 2.6 \\
81.0\end{array}$ & $\begin{array}{l}12.5 \pm 2.4 \\
89.3\end{array}$ & $\begin{array}{l}11.9 \pm 2.7 \\
76.8\end{array}$ & $\begin{array}{l}12.8 \pm 2.7 \\
82.0\end{array}$ & $\begin{array}{l}12.8 \pm 2.7 \\
82.5\end{array}$ \\
\hline PUFA (5-10 E\%) & $\begin{array}{l}6.1 \pm 1.7 \\
73.4\end{array}$ & $\begin{array}{l}6.3 \pm 1.7 \\
77.0\end{array}$ & $\begin{array}{l}6.7 \pm 1.9 * * \\
81.0\end{array}$ & $\begin{array}{l}6.4 \pm 1.8 \\
75.4\end{array}$ & $\begin{array}{l}6.6 \pm 1.8 * \\
68.9\end{array}$ & $\begin{array}{l}6.8 \pm 2.1 * * \\
78.4\end{array}$ \\
\hline Protein $\left(10-20 \mathrm{E} \%^{\mathrm{a}}\right)$ & $\begin{array}{l}17.1 \pm 3.1 \\
80.5\end{array}$ & $\begin{array}{l}16.8 \pm 2.8 \\
86.2\end{array}$ & $\begin{array}{l}15.7 \pm 2.8 * * * \\
89.3\end{array}$ & $\begin{array}{l}15.5 \pm 3.0^{* * * *} \\
89.9\end{array}$ & $\begin{array}{l}17.3 \pm 3.0 \\
86.9\end{array}$ & $\begin{array}{l}16.4 \pm 3.1 * \\
84.5\end{array}$ \\
\hline Protein $(\mathrm{g} / \mathrm{kg})$ & $1.12 \pm 0.33$ & $1.05 \pm 0.29 * *$ & $0.88 \pm 0.27 * * *$ & $0.96 \pm 0.29 * * *$ & $1.12 \pm 0.33$ & $0.99 \pm 0.34 * * *$ \\
\hline
\end{tabular}

Data are presented as mean \pm SD intake of a given nutrient, and percentages of individuals reaching the respective recommendations. Although all values were not normally distributed, we chose to present mean \pm SD values to enable comparison between the groups

The difference in the nutrient intakes, between those adhering and not adhering to a special diet, has been calculated with Mann-Whiney $U$ test. The difference in the frequencies of meeting the dietary recommendations has been calculated with Chi-squared test

$E \%$ percentage of total energy intake, SAFA saturated fatty acids, MUFA monounsaturated fatty acids, PUFA polyunsaturated fatty acids $* P<0.05$; ** $P<0.01 ; * * * P<0.001$

${ }^{\mathrm{a}} 15-20 \mathrm{E} \%$ in those above 65 years

\section{Discussion}

In a large population of individuals with type 1 diabetes, we observed that as much as $36.6 \%$ followed some sort of special diet. Of the special diets, a lactose-free diet was the most prevalent, followed by protein restricted, vegetarian, and gluten-free diets. Moreover, $10 \%$ of the respondents reported adhering to more than one special diet. Those 
Table 5 Mean vitamin and micronutrient densities of the study subjects completing the food record $(n=1040)$, and percentages of individuals reaching the recommendations divided by self-reported adherence to a special diet

\begin{tabular}{|c|c|c|c|c|c|c|}
\hline Nutrient (recommendation/MJ) & $\begin{array}{l}\text { None } \\
n=673(64.7 \%)\end{array}$ & $\begin{array}{l}\text { Lactose-free } \\
n=174(16.7 \%)\end{array}$ & $\begin{array}{l}\text { Protein restriction } \\
n=84(8.1 \%)\end{array}$ & $\begin{array}{l}\text { Vegetarian } \\
n=69(6.6 \%)\end{array}$ & $\begin{array}{l}\text { Gluten-free } \\
n=61(5.9 \%)\end{array}$ & $\begin{array}{l}\text { Multiple diets } \\
n=97(9.3 \%)\end{array}$ \\
\hline \multirow[t]{2}{*}{ Vitamin A (80 RE) } & $115 \pm 98$ & $114 \pm 79$ & $146 \pm 179 * * *$ & $140 \pm 188^{*}$ & $182 \pm 266^{* *}$ & $149 \pm 207 * *$ \\
\hline & 64.0 & 67.2 & $81.0 * *$ & $78.3^{*}$ & $78.7 *$ & $78.4 * *$ \\
\hline \multirow[t]{2}{*}{ Vitamin D $(1.4 \mu \mathrm{g})$} & $1.1 \pm 0.6$ & $1.0 \pm 0.5^{* *}$ & $1.1 \pm 0.6$ & $1.0 \pm 0.7 *$ & $1.0 \pm 0.7 * *$ & $1.0 \pm 0.7$ \\
\hline & 26.2 & $16.7 * *$ & 25.0 & 26.1 & 18.0 & 24.7 \\
\hline \multirow[t]{2}{*}{ Vitamin E $(0.9 \alpha$-TE $)$} & $1.3 \pm 0.4$ & $1.4 \pm 0.4$ & $1.4 \pm 0.3 * *$ & $1.4 \pm 0.4^{*}$ & $1.4 \pm 0.3 *$ & $1.5 \pm 0.4 * *$ \\
\hline & 94.2 & 97.7 & 98.8 & 95.7 & 98.4 & 97.9 \\
\hline \multirow[t]{2}{*}{ Thiamine $(0.12 \mathrm{mg})$} & $0.19 \pm 0.05$ & $0.19 \pm 0.04$ & $0.19 \pm 0.05$ & $0.18 \pm 0.04$ & $0.19 \pm 0.04$ & $0.19 \pm 0.04$ \\
\hline & 97.5 & 94.8 & 98.8 & 98.6 & 95.1 & 96.9 \\
\hline \multirow[t]{2}{*}{ Riboflavin (0.14 mg) } & $0.25 \pm 0.06$ & $0.23 \pm 0.06^{* *}$ & $0.22 \pm 0.06^{* * *}$ & $0.23 \pm 0.06^{*}$ & $0.25 \pm 0.07$ & $0.23 \pm 0.06^{* *}$ \\
\hline & 99.0 & 97.1 & $95.2^{*}$ & 98.6 & 98.4 & $94.8^{*}$ \\
\hline \multirow[t]{2}{*}{ Niacin (1.6 NE) } & $2.1 \pm 0.9$ & $2.1 \pm 0.9$ & $1.8 \pm 0.7 * *$ & $2.1 \pm 0.7$ & $2.4 \pm 1.1 *$ & $2.2 \pm 1.0$ \\
\hline & 70.6 & 67.2 & 61.9 & 68.1 & 73.8 & 73.2 \\
\hline \multirow[t]{2}{*}{ Vitamin B6 (0.2 mg) } & $0.3 \pm 0.1$ & $0.3 \pm 0.1$ & $0.2 \pm 0.1$ & $0.2 \pm 0.1 * *$ & $0.3 \pm 0.1 * * *$ & $0.3 \pm 0.1$ \\
\hline & 99.4 & 100 & 100 & 100 & 100 & 100 \\
\hline \multirow[t]{2}{*}{ Folate $(45 \mu \mathrm{g})$} & $36 \pm 11$ & $38 \pm 10^{*}$ & $40 \pm 15^{*}$ & $46 \pm 16^{* * *}$ & $44 \pm 20 * *$ & $42 \pm 17 * * *$ \\
\hline & 15.2 & $21.8^{*}$ & 20.2 & $42.0 * * *$ & $36.1 * * *$ & $30.9 * * *$ \\
\hline \multirow[t]{2}{*}{ Vitamin C (8 mg) } & $16 \pm 9$ & $18 \pm 9 *$ & $19 \pm 10^{* *}$ & $20 \pm 8 * * *$ & $21 \pm 13 * *$ & $20 \pm 11 * * *$ \\
\hline & 84.8 & 89.7 & $92.9 *$ & 91.3 & 93.4 & 91.8 \\
\hline \multirow[t]{2}{*}{ Calcium (100 mg) } & $137 \pm 39$ & $132 \pm 41$ & $110 \pm 38 * * *$ & $134 \pm 36$ & $133 \pm 41$ & $121 \pm 41 * * *$ \\
\hline & 81.3 & 79.3 & $53.6^{* * *}$ & 81.2 & 75.4 & $68.0 * *$ \\
\hline \multirow[t]{2}{*}{ Phosphorus (80 mg) } & $200 \pm 35$ & $193 \pm 40 * *$ & $179 \pm 36^{* * *}$ & $191 \pm 32 *$ & $195 \pm 45$ & $187 \pm 43 * * *$ \\
\hline & 100 & 100 & 100 & 100 & 100 & 100 \\
\hline \multirow[t]{2}{*}{ Potassium (350 mg) } & $504 \pm 101$ & $502 \pm 104$ & $497 \pm 117$ & $515 \pm 111$ & $528 \pm 113$ & $514 \pm 110$ \\
\hline & 94.5 & 94.3 & 89.3 & 92.8 & 95.1 & 91.8 \\
\hline \multirow[t]{2}{*}{ Magnesium (32 mg) } & $48 \pm 8$ & $48 \pm 10$ & $46 \pm 10$ & $52 \pm 11 * *$ & $48 \pm 10$ & $49 \pm 11$ \\
\hline & 98.1 & 95.4 & 96.4 & 98.6 & $93.4 *$ & $93.8 *$ \\
\hline \multirow[t]{2}{*}{ Iron $(1.6 \mathrm{mg})$} & $1.6 \pm 0.4$ & $1.6 \pm 0.4$ & $1.7 \pm 0.4^{*}$ & $1.7 \pm 0.4 * *$ & $1.6 \pm 0.4$ & $1.7 \pm 0.4^{*}$ \\
\hline & 47.7 & 48.9 & $59.5 *$ & $63.8^{*}$ & 45.9 & 58.8 \\
\hline \multirow[t]{2}{*}{ Zinc (1.2 mg) } & $1.6 \pm 0.3$ & $1.5 \pm 0.3$ & $1.5 \pm 0.3^{*}$ & $1.4 \pm 0.3 * * *$ & $1.5 \pm 0.3 * * *$ & $1.5 \pm 0.3 * *$ \\
\hline & 95.7 & 93.7 & $88.1^{* *}$ & $82.6^{* * *}$ & $80.3^{* * *}$ & $86.6^{* *}$ \\
\hline \multirow[t]{2}{*}{ Copper $(0.1 \mathrm{mg})$} & $0.2 \pm 0.0$ & $0.2 \pm 0.1 * *$ & $0.2 \pm 0.1$ & $0.2 \pm 0.1 * * *$ & $0.2 \pm 0.1 * * *$ & $0.2 \pm 0.1 * * *$ \\
\hline & 99.1 & 100 & 100 & 100 & 100 & 100 \\
\hline \multirow[t]{2}{*}{ Iodine $(17 \mu \mathrm{g})$} & $28 \pm 8$ & $26 \pm 6^{*}$ & $24 \pm 5^{* * *}$ & $26 \pm 10^{*}$ & $27 \pm 7$ & $25 \pm 7 * * *$ \\
\hline & 97.5 & $94.3^{*}$ & $92.9^{*}$ & $84.1 * * *$ & 98.4 & $90.7 * *$ \\
\hline \multirow[t]{2}{*}{ Selenium $(5.7 \mu \mathrm{g})$} & $8.9 \pm 2.4$ & $8.6 \pm 2.3$ & $8.2 \pm 1.8^{*}$ & $8.0 \pm 2.1 * *$ & $9.4 \pm 2.3^{*}$ & $8.6 \pm 2.2$ \\
\hline & 97.3 & 98.3 & $92.9^{*}$ & $88.4 * *$ & 100 & 94.8 \\
\hline
\end{tabular}

Data are presented as mean \pm SD intake of a given nutrient, and percentages of individuals reaching the respective recommendations. Although all values were not normally distributed, we chose to present mean \pm SD values to enable comparison between the groups. The difference in the nutrient intakes, between those adhering and not adhering to a special diet, has been calculated with the Mann-Whiney $U$ test. The difference in the frequencies of meeting the dietary recommendations has been calculated with Chi-squared test

$* P<0.05 ; * * P<0.01 ; * * * P<0.001$

adhering to any special diet, had longer diabetes duration, were more frequently women, and based on the clinical characteristics seemed sicker than the ones not adhering to special diets.

Compared to the studies conducted in the general population in Italy (6.2\%) [5] and in USA (2.9\%) [6], the rate of adhering to special diets, in the current study, was substantially higher. This difference is most likely explained by differences in the study populations. First, type 1 diabetes is frequently associated with coeliac disease. Compared to the estimated $0.5 \%$ prevalence of coeliac disease in the general population, rates between 4.4 and $11.1 \%$ have been reported 
in type 1 diabetes [12]. With the $5.6 \%$ rate of adherence to gluten-free diet, our observation is well in concordance with the previous results. Second, due to a high prevalence of nephropathy among individuals with type 1 diabetes [13], a substantial number of individuals with protein restriction may be expected. Moreover, due to the nature of their metabolic disease, individuals with type 1 diabetes may be more aware of the role of the diet for their health, and may be more open to explore the effects of different diets compared to individuals with no particular issues with their health.

The female predominance amongst special diet adherents has previously been shown in the American general population [6]. Moreover, in the same study, the highest proportion of individuals adhering to special diets were observed in those aged 50-64 years, and the special diets were mainly used to improve overall health. These data are comparable to our observations, as individuals reporting special diets were somewhat older, and more specifically had a longer higher diabetes duration. In addition to the longer diabetes duration, the individuals with special diets had more diabetes complications, which could suggest that the special diets were used for health reasons.

Based on our observations with the diet patterns, compared to those with no special diet, adherence to some of the special diets was associated with more prudent food choices. In particular, higher intakes of vegetables, legumes, fruits, berries, and fish were seen in those adhering to lactose-free, protein restricted, and vegetarian diets. Moreover, lower factor scores in the "Soft drinks" pattern were observed in those on lactose-free and protein restricted diets. In emerging kidney disease, protein restriction is accompanied with phosphorus restriction. As soft drinks commonly contain phosphoric acids, lower intakes of soft drinks, among those reporting protein restriction, were an expected phenomenon. We were not able to identify other studies where diet patterns in relation to adherence to special diets have been investigated.

As expected, carbohydrates provided most of the energy in all diet groups, followed by fats and proteins. Carbohydrate intakes, however, were close to the lower levels of the recommendations in all groups. Low-carbohydrate intakes were reflected in low mean fibre intakes, which were below the recommendations in all groups. Of all the groups, however, vegetarians had the highest fibre intakes, while those adhering to gluten-free diets had the lowest. Omission of gluten-containing grains, in those on gluten-free diet, likely contributes to the latter observation. Based on our current observations, increasing fibre intake from vegetable sources and suitable grain sources could be beneficial in all diet groups.

Of the micronutrients, the recommendations for vitamin $\mathrm{D}$, folate, and iron were, regardless of the diet, most frequently unmet. These results are well in concordance with the results from The National FINDIET 2012 survey, which identified these three micronutrients as the ones whose intakes are frequently suboptimal in the Finnish population [14]. In the current study, individuals on lactose-free diet, potentially due to the avoidance of vitamin $\mathrm{D}$ fortified milk products, were amongst those with the lowest frequency of meeting vitamin D recommendations. Moreover, only less than one in five of those on gluten-free diet met the recommendations for vitamin D intake. Increasing the consumption of fish dishes, and fortified milk products and dietary fats would increase vitamin D intake in the current population. To achieve the recommendations, however, intake from supplements, especially at the northern latitudes, may be required.

The highest folate intakes, in the current study, were observed in vegetarians, and in those on gluten-free diet. Despite these higher intakes on a group level, more than half of these individuals failed to meet the folate recommendations. In the National FINDIET 2012 survey, mean energyadjusted folate intake in the Finnish population was $32 \mu \mathrm{g} /$ MJ [14]. While the intake in all the current diet groups was, on average, higher than these national values, individuals in all diet groups could benefit from increasing the consumption of green leafy vegetables, fruits and berries, grains, and legumes, as these are good sources of folate.

Finally, iron recommendations were most frequently unmet among those on gluten-free diets, lactose-free diet, and in those with no special diets. While grains are generally a fairly good source of iron, other, more suitable sources for individuals particularly on gluten-free diet would be various meats, organ foods, seeds, and spinach, for example.

A large population of well-defined individuals with type 1 diabetes, and the use of a validated diet questionnaire are the major strengths of this study. However, it is likely that some selection bias may have occurred, overemphasising the proportion of individuals more interested in health issues and diet. Whether or not this would reflect on the frequencies of adhering to various special diets is, however, not known. A cross-sectional study design is suitable for identifying the frequencies of adherence to special diets and for evaluating the dietary intake in these groups. It may also be successfully used to identify the clinical characteristics of the individuals adhering to each of the diets. These data should, however, not be used to draw conclusions about the health effects of adhering to the given special diets. Instead, it is more plausible that special diets are frequently initiated based on a clinical requirement, as is the case with protein restriction and gluten-free diets, for example. Importantly, these data will be used as baseline for longitudinal analyses, in the future, when associations between diet and health consequences will be evaluated.

In conclusion, our study shows that adherence to special diets was common in individuals with type 1 diabetes. 
Special diet adherents were predominantly women, and had longer diabetes duration and also more diabetes complications. While some differences in the nutrient intakes, between the different diet groups, were identified, a general observation was that the intakes of fibre, vitamin $\mathrm{D}$, folate, and iron fell short of the recommendations, in all groups.

Acknowledgements The skilled technical assistance of Anna Sandelin, Mira Korolainen, and Jaana Tuomikangas is gratefully acknowledged. The authors also acknowledge all the physicians and nurses at each centre participating in the collection of patients (online appendix).

Funding This study was supported by grants from Academy of Finland, Novo Nordisk Foundation, Signe and Ane Gyllenberg Foundation, Folkhälsan Research Foundation, Wilhelm and Else Stockmann Foundation, Liv och Hälsa Foundation, the Helsinki University Central Hospital Research Funds, Päivikki and Sakari Sohlberg Foundation, and Diabetes Wellness Finland. Funding agencies did not contribute to the study design, conduct of the study, data analysis, interpretation of the findings, writing of the manuscript, or in the decision to submit the manuscript for publication.

\section{Compliance with ethical standards}

Conflict of interest Professor Per-Henrik Groop has received research grants from Eli Lilly and Roche, is an advisory board member for AbbVie, Astra Zeneca, Boehringer-Ingelheim, Cebix, Eli Lilly, Janssen, MSD, Medscape, Novartis, Novo Nordisk, and Sanofi. He has received lecture honoraria from Astra Zeneca, Boehringer-Ingelheim, Eli Lilly, Elo Water, Genzyme, MSD, Novartis, Novo Nordisk, and Sanofi. All other authors declare no conflicts of interest.

Ethical standard All procedures performed in the study were in accordance with the ethical standards of the institutional research committee and with the 1964 Helsinki declaration and its later amendments or comparable ethical standards.

Informed consent Informed consent was obtained from all individual participants included in the study.

\section{References}

1. Evert AB, Boucher JL, Cypress M et al (2014) Nutrition therapy recommendations for the management of adults with diabetes. Diabetes Care 37(Suppl 1):S120-S143
2. Lawton J, Rankin D, Cooke DD et al (2011) Dose adjustment for normal eating: a qualitative longitudinal exploration of the food and eating practices of type 1 diabetes patients converted to flexible intensive insulin therapy in the UK. Diabetes Res Clin Pract 91:87-93

3. Nordic Nutrition Recommendations (2012) Integrating nutrition and physical activity, 5th edn. Nordic Council of Ministers. https ://www.evira.fi/globalassets/vrn/pdf/nordic-nutrition-recommenda tions-2012.pdf. Accessed 9 Feb 2018

4. Finnish Nutrition Recommendations (2014) https://www.evira .fi/globalassets/vrn/pdf/ravitsemussuositukset_terveytta-ruoas ta_2014_fi_web_v4.pdf. Accessed 9 Feb 2018

5. Pounis G, Bonanni A, Ruggiero E et al (2017) Food group consumption in an Italian population using the updated food classification system FoodEx2: results from the Italian nutrition \& HEalth survey (INHES) study. Nutr Metab Cardiovasc Dis 27:307-328

6. Leung B, Lauche R, Leach $\mathrm{M}$ et al (2017) Special diets in modern America: analysis of the 2012 National Health Interview Survey data. Nutr Health. https://doi.org/10.1177/0260106017732719

7. Ahola AJ, Lassenius MI, Forsblom C et al (2017) Dietary patterns reflecting healthy food choices are associated with lower serum LPS activity. Sci Rep 7:6511. https://doi.org/10.1038/s41598-01706885-7

8. Ahola AJ, Mikkilä V, Mäkimattila S et al (2012) Energy and nutrient intakes and adherence to dietary guidelines among Finnish adults with type 1 diabetes. Ann Med 44:73-81

9. Ahola AJ, Saraheimo M, Freese R et al (2016) Fear of hypoglycaemia and self-management in type 1 diabetes. J Clin Transl Endocrinol 4:13-18

10. Ahola AJ, Thorn LM, Saraheimo M et al (2010) Depression is associated with the metabolic syndrome among patients with type 1 diabetes. Ann Med 42:495-501

11. Levey AS, Stevens LA, Schmid CH et al (2009) A new equation to estimate glomerular filtration rate. Ann Intern Med 150:604-612

12. Camarca ME, Mozzillo E, Nugnes R et al (2012) Celiac disease in type 1 diabetes mellitus. Ital J Pediatr. https://doi. org/10.1186/1824-7288-38-10

13. Hovind P, Tarnow L, Rossing K et al (2003) Decreasing incidence of severe diabetic microangiopathy in type 1 diabetes. Diabetes Care 26:1258-1264

14. Helldán A, Raulio S, Kosola M et al (2013) The National FINDIET 2012 Survey. https://www.julkari.fi/bitstream/handl e/10024/110839/THL_RAP2013_016_\%26sliitteet.pdf. Accessed 9 Feb 2018 